\title{
COMMENTARY
}

\section{Fluid-induced coagulopathy: does the type of fluid make a difference?}

\author{
Gernot Marx* and Tobias Schuerholz \\ See related research of Sossdorf et al., http://ccforum.com/content/13/6/R208
}

\begin{abstract}
Crystalloid and colloid solutions are used for resuscitation of the critically ill. One set of options, widely used today, are different preparations of hydroxyethyl starch (HES). However, the safety of HES regarding impairment of blood coagulation remains incompletely elucidated, a circumstance that limits its clinical use. Understanding mechanisms and potential differences between low-molecular and low-substituted HES and other HES solutions seems clinically relevant.
\end{abstract}

Since recognizing platelets as an important part in coagulation some 125 years ago, the scientific community has evaluated platelets as a key player between inflammation and coagulation. Critically ill patients suffer from both inflammation and impaired coagulation. Thus, it is essential to learn more about the mutual influence between these two problems during intensive care therapy.

In this context, Sossdorf and colleagues [1] evaluated the impact of hydroxyethyl starch (HES) on thrombelastography and platelet receptors. The authors investigated 10\% HES 200/0.5, 6\% HES 130/0.4, and saline in an in vitro experiment with blood of healthy volunteers [1]. HESs are considered effective plasma volume expanders in clinical practice [2]. Adverse effects of HES administration on hemostasis have spurred ongoing research into the pathological mechanisms since these effects are continually discussed as a serious limitation to the clinical use of HES [2]. Sossdorf and colleagues [1] could reveal a decreased maximum clot firmness in FIBTEM (rotation thromboelastometry [ROTEM $\left.{ }^{\circ}\right]$-based measurement of

*Correspondence: gmarx@ukaachen.de

Department of Intensive Care, University Hospital Aachen, RWTH Aachen University, Pauwelsstrasse 30, 52074 Aachen, Germany the contribution of fibrinogen to the clot firmness) with a $10 \%$ hemodilution by both tested HES solutions compared with saline. Other parameters of ROTEM ${ }^{\circ}$ were affected by HES 200/0.5 but not by HES 130/0.4. A higher hemodilution of $40 \%$ showed comparable results for the two HESs. Accordingly, Innerhofer and colleagues [3] could demonstrate an inhibition of primary hemostasis by HES 200/0.5 and gelatine.

Sossdorf and colleagues further demonstrated that a clinical reasonable hemodilution of $10 \%$ does not affect the tested platelet receptors with both HESs when compared with saline after activation with adenosine-diphosphate (ADP) or thrombin receptor agonist peptide (TRAP). Without the addition of an agonist, the authors detected a significant $3 \%$ to $5 \%$ difference of plateletneutrophil conjugates after 10\% hemodilution with $6 \%$ HES 130/0.4. In contrast, 10\% HES 200/0.5 may adhere to the platelet surface and decrease ligand binding to the fibrinogen receptor with a hemodilution of $10 \%$ or more. Additionally, it was shown that the risk of bleeding is associated with synthetic colloids of higher molecular weight and higher degree of substitution [4].

A decreased P-selectin expression after activation with ADP in a $10 \%$ hemodilution with HES $130 / 0.4$ is not necessarily in line with the proposed pro-inflammatory action of HES. Yet the binding of P-selectin induces tissue factor expression on neutrophils [5], and in a positive feedback loop, neutrophils activate platelets as measured by P-selectin expression [6]. Moreover, platelets are able to act via a P-selectin-independent pathway to activate neutrophils and to contribute to the formation of neutrophil extracellular traps [7]. It would be interesting to further investigate the TLR4 (Toll-like receptor 4) expression in patients with bacteremia and sepsis.

The question therefore is whether there are important different effects between HES solutions on blood coagulation. HES solutions vary widely with respect to their physiochemical characteristics, hence the concentration, molecular weight, degree of substitution, and C2/ C6 ratio account for differences in their pharmacokinetic and pharmacodynamic profile [8]. With their in vitro 
data, Sossdorf and colleagues further the discussion on effects of different HES solutions in this area. In vitro studies are limited because of the absence of the endothelium and compensatory mechanisms like buffering and the control of $\mathrm{pH}$ and the lack of other electrolytes and metabolic degradation. Furthermore, it was shown that 130/0.42 dissolved in a balanced solution containing calcium was associated with fewer negative effects on thrombelastrography than HES 130/0.4 dissolved in a solution without calcium [9]. Thus, more in vivo experiments seem to be important to increase the evidence of effects of various especially fast degradable HES preparations in patients undergoing surgery with major blood loss or in critically ill patients, especially those with sepsis. It seems of utmost importance to distinguish very clearly between different clinical settings in order to identify underlying mechanisms of HES solutions on coagulation.

Abbreviations

ADP = adenosine-di-phosphate; $\mathrm{HES}=$ hydroxyethyl starch; $\mathrm{ROTEM}^{\circ}=$ rotation thromboelastometry.

\section{Competing interests}

GM has done paid consultation and verbal presentations for B. Braun Melsungen AG (Melsungen, Germany), has performed research projects in collaboration with B. Braun Melsungen AG and has thereby received other funding in the past, and has received presentation fees and research project funds from Serumwerk Bernburg AG (Bernburg, Germany). TS has received funding from B. Braun Melsungen AG for a research project.

Published: 15 February 2010
References

1. Sossdorf M, Marx S, Schaarschmidt B, Otto GP, Claus RA, Reinhart K, Hartog CS, Loesche W: HES130/0.4 impairs haemostasis and stimulates proinflammatory blood platelet function. Crit Care 2009, 13:R208.

2. Westphal M, James MF, Kozek-Langenecker S, Stocker R, Guidet B, Van Aken $\mathrm{H}$ : Hydroxyethyl starches: different products--different effects. Anesthesiology 2009, 111:187-202.

3. Innerhofer P, Fries D, Margreiter J, Klingler A, Kühbacher G, Wachter B, Oswald E, Salner E, Frischhut B, Schobersberger W: The effects of perioperatively administered colloids and crystalloids on primary platelet-mediated hemostasis and clot formation. Anesth Analg 2002, 95:858-865, table of contents.

4. Franz A, Bräunlich P, Gamsjäger T, Felfernig M, Gustorff B, Kozek-Langenecker SA: The effects of hydroxyethyl starches of varying molecular weights on platelet function. Anesth Analg 2001, 92:1402-1407.

5. Maugeri N, Brambilla M, Camera M, Carbone A, Tremoli E, Donati MB, de Gaetano G, Cerletti C: Human polymorphonuclear leukocytes produce and express functional tissue factor upon stimulation. J Thromb Haemost 2006, 4:1323-1330.

6. Pluskota E, Woody NM, Szpak D, Ballantyne CM, Soloviev DA, Simon DI, Plow EF: Expression, activation, and function of integrin alphaMbeta2 (Mac-1) on neutrophil-derived microparticles. Blood 2008, 112:2327-2335.

7. Clark SR, Ma AC, Tavener SA, McDonald B, Goodarzi Z, Kelly MM, Patel KD, Chakrabarti S, McAvoy E, Sinclair GD, Keys EM, Allen-Vercoe E, Devinney R, Doig CJ, Green FH, Kubes P: Platelet TLR4 activates neutrophil extracellular traps to ensnare bacteria in septic blood. Nat Med 2007, 13:463-469.

8. Lehmann GB, Asskali F, Boll M, Burmeister MA, Marx G, Hilgers R, Forster H: HES 130/0.42 shows less alteration of pharmacokinetics than HES 200/0.5 when dosed repeatedly. Br J Anaesth 2007, 98:635-644.

9. Boldt J, Mengistu A: Balanced hydroxyethylstarch preparations: are they al the same? In-vitro thrombelastometry and whole blood aggregometry. Eur J Anaesthesio/ 2009, 26:1020-1025.

doi: $10.1186 /$ cc8841

Cite this article as: Marx G, Schürholz T: Fluid-induced coagulopathy: does the type of fluid make a difference? Critical Care 2010, 14:1 18. 